\title{
Global Income Inequality in Numbers: in History and Now ${ }^{1}$
}

\section{Branko Milanovic}

\section{Abstract}

This article presents an overview of calculations of global inequality, recently and over the long term, and outlines the main controversies and political and philosophical implications of the findings. It focuses in particular on the winners and losers of the most recent episode of globalization, from 1988 to 2008. It suggests that the period has witnessed the first decline in inequality between world citizens since the Industrial Revolution. However, the decline can be sustained only if countries' mean incomes continue to converge (as they have been doing during the past ten years) and if internal (within-country) inequalities, which are already high, are kept in check. Mean-income convergence would also reduce the huge 'citizenship premium' that is enjoyed today by the citizens of rich countries.

When we think of income inequality, our first reaction is to think of it within the borders of a country. This is quite understandable in a world where the nation state is very important in determining one's income level and access to a number of benefits (from pensions to free health care), and where by far the dominant way in which political life is organized is at the level of a country. However, in the era of globalization another way to look at inequality between individuals is to go beyond the confines of a nation state and to look at inequality between all individuals in the world. Once we do so, many of the things about inequalities in general that we believe or think we know change; it is like going from a two-dimensional world to a three-dimensional one.

As the world becomes more integrated, the global dimension of inequality is likely to become increasingly relevant. This is for at least two reasons: the muchincreased movement of factors of production across borders, and the greater influence of other people's (foreigners') standard of living and way of life on one's perceived income position and aspirations. Greater movement of capital, goods, technology and ideas from one side of the globe to another implies greater connectivity with people who are not one's compatriots, and greater dependence on other nations for the generation of one's income. Movements of labor that illustrate this interdependence in a most obvious fashion are still less important than movements of capital, but they are increasing. The knowledge of how other people live and how much money they make influences strongly our perception of our own income and position in the income pyramid. An imaginary community of world citi- zens is thus built gradually. And once this is done, comparisons of actual incomes and welfare between different members of that imaginary community acquire importance. This is why global inequality will gain in importance, even if it is not as relevant or important for an average individual as inequality within his or her political community (nation state). Once we compare ourselves with people from other parts of the world, we are indeed interested in global income distribution. Global inequality begins to matter.

1. Three concepts of inequality and how they have evolved over the past 60 years

When we talk about inequality that transcends national borders, often we have in mind not one but three different concepts - even when we are not fully aware of it. I am going to articulate these three concepts.

The first concept of inequality (let's call it inequality 1) is focused on inequality between nations of the world. It is an inequality statistic calculated across GDPs or mean incomes obtained from household surveys of all countries in the world, without population weighting. To show how this is done, consider the three individuals in the top row of Figure 1. The height of each person represents the GDP or mean income of his or her country. Somebody from a poor country would be represented as a short person, somebody from a middle-income country as a person of medium height, and somebody from a rich country as a very tall person. When we calculate this concept of inequality, we take all countries with their mean incomes - we have data for some 150 countries - 
Figure 1. Three concepts of inequality defined.

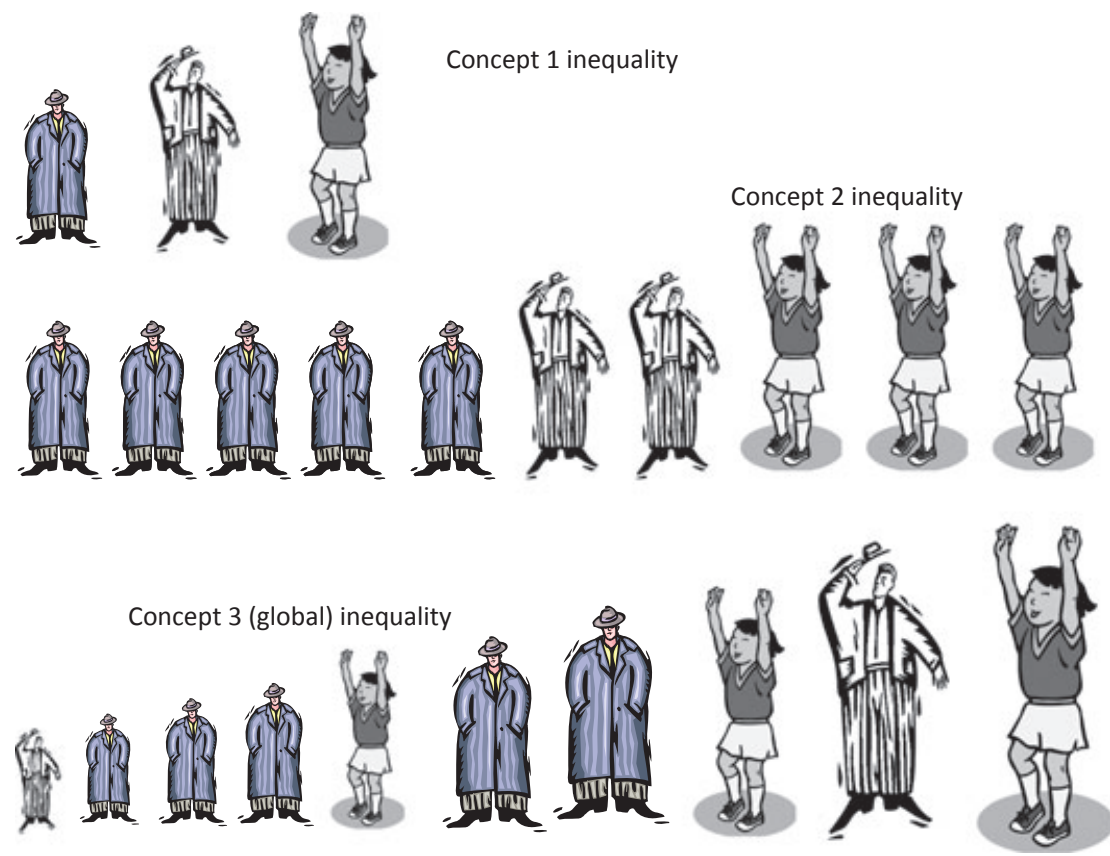

and calculate the Gini coefficient. ${ }^{2}$ China and Luxembourg have the same importance, because we do not take population sizes into account. Every country counts the same, somewhat like in the UN General Assembly.

Consider now the second row of the figure, which would help us define concept 2 inequality or inequality 2 . There, individuals from poor countries are all equally short as before and those from rich countries are all equally tall, but the difference lies in the fact that countries' population sizes are now taken into account. We do exactly the same thing as we did for inequality 1, but now China and Luxemburg (or any other country) enter the calculation with their populations. Introducing population is very important. As we shall see in the next section, during the past 25 years the movements in concept 1 and concept 2 inequalities were very different. Recall, however, that in both cases the calculation takes into account not the actual incomes of individuals but country averages.

Inequality 3 is the global inequality, which is the most important concept for those interested in the world as composed of individuals, not nations. Unlike the first two concepts, this one is individual-based: each person, regardless of his or her country, enters in the calculation with their actual income. In Figure 1, this is represented by the different heights of individuals who belong to the same country. Not all Americans earn the average income of the US, nor do all Chinese earn the average income of China. Indeed in row 3, the poorest person is from the middle-income country, while his compatriot is the second richest (the second tallest) in our group of ten individuals.

But moving from concept 2 to concept 3 inequality is not easy. The chief difficulty comes from the fact that to calculate concept 3 inequality we need access to household surveys with data on individual incomes or consumption. Income or consumption have to be measured using the same or similar methodology, and surveys need to be available from as many countries as possible. Perhaps at least 120-130 surveys are needed in order to cover more than 90 per cent of the world population and account for 95 or more per cent of world income. ${ }^{3}$ Ideally, of course, we would like to have surveys from every country in the world. This is a very hard requirement. There are still quite a few countries, mostly in Africa, where household surveys are not conducted regularly and where methodologies change (sometimes rather brusquely) from one survey to another, thus rendering comparisons difficult.

Because the calculation of global inequality relies on household surveys, we cannot calculate inequality 3 with much precision for the period before the mid- or late 1980s. There are simply no household surveys available for many parts of the world. The first available Chinese household surveys are from 1982, the first usable surveys from the former Soviet Union are from 1988, and for many sub-Saharan African countries, the earliest household surveys date from the mid-1980s. Thus, for the past, we have to rely on much more tentative data, where countries' income distributions are only approximated 
using various more or less reliable methods. This is particularly the case if we wish to study global inequality over the long term, covering the $19^{\text {th }}$ century as well $-\mathrm{a}$ topic that I will discuss in Section 3.

Figure 2 displays the movements of the three types of inequalities after the Second World War. The Gini coefficient is on the vertical axis. Inequality 1 was stable from 1960 to 1980 . This means that there was no systematically faster or slower growth of poor or rich countries. The gap between poor and rich countries was neither closing nor growing. Divergence started only at the beginning of globalization, around 1980, and went on until the turn of the century. These two decades were very bad as far as convergence (or catching up by poor countries) is concerned: rich countries grew, on average, faster than poor countries. However China and India, which are the huge success stories of that period and the two most populous countries in the world, do not enter into the calculation of inequality 1 with greater weights than any other country.

Let us now consider further Figure 2. Why is it called 'the mother of all inequality disputes'? To see what the dispute is about, consider the difference in the movements of inequality 1 and inequality 2 . While the first, as we just saw, rose during the globalization era, the second declined - at times even dramatically. Measured by inequality 2 , the world has certainly become a much better ('more convergent' or more equal) place precisely during the same period. Thus, those who desire to emphasize the unevenness of globalization tend to focus on growing inter-country gaps without taking into account sizes of population, and prefer inequality 1 . Those who wish to focus on the positive aspects of globalization tend to favor concept 2, and to point to the indubitable successes of China and India. In effect, to

Figure 2. International and global inequality, 1952-2011: 'the mother of all inequality disputes'.

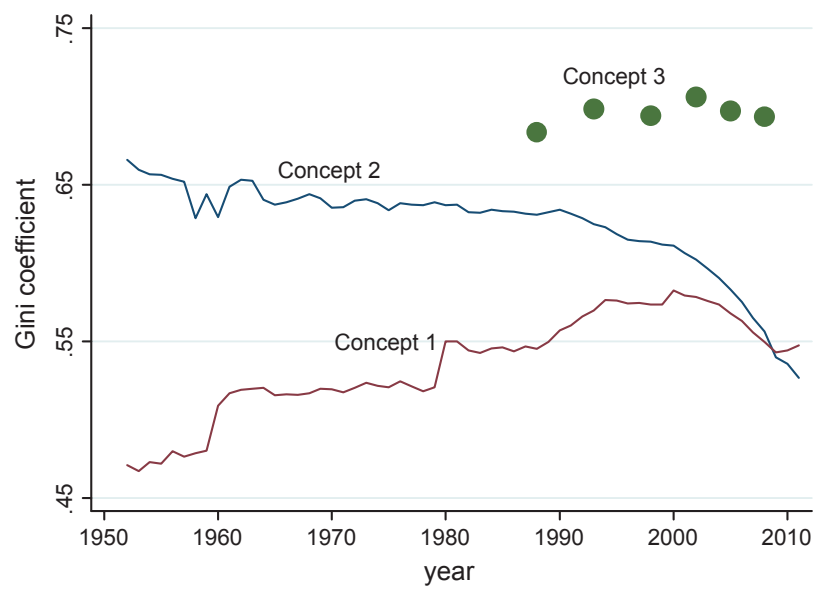

grasp intuitively why and how concept 2 inequality declined, we need to recall that in these calculations, China counts for a lot because of its large population size. And China, which started from an extremely low level of income in the 1980s, has grown very quickly during the past three decades, converging on the rich world. Until recently, it was China alone that had been preventing a rise in global inequality as measured by concept 2 . But now it has 'support' from India, which is also recording high rates of growth and has also started from a very low baseline. The high rates of growth of these two countries are thus the major factor underlying the downward trend of inequality 2 .

Inequality 3 can be calculated, as mentioned earlier, only from the mid-1980s because we do not have household surveys that go back further in time. Figure 2 shows that inequality 3 is higher than inequality 2 . This is true by definition: in inequality 3 people enter the calculations with their actual incomes, not with country averages. A quick glance at Figure 1 shows that the variability of heights is greater in the third row than in the second. Averaging out reduces measured inequality.

To calculate 'true' global inequality, we have to adjust people's incomes with the price levels they face; of course, these differ between countries. We are interested in the real welfare of people, and those living in 'cheaper' countries will get a boost in their incomes compared to what they make in nominal dollar terms. The currency we use is the international (or purchasing power parity (PPP)) dollar with which, in principle, one can buy the same amount of goods and services in any country. Indeed, if we were not to adjust for the differences in price levels, and were to use nominal dollars, global inequality would have been even higher. This is because price levels tend to be lower in poorer countries, and the income of people living in poorer countries thus gets a significant 'boost' when we use PPP dollars.

Often, a key issue of concern regarding global inequality is not only its level but its trend: has it been going up or down during the globalization era? Global inequality is calculated at approximately five-year intervals, from 1988 (the first dot on the left in Figure 2) to 2008 (the last dot on the right). If we compare this last dot with a couple of dots for the earlier years, we see something that may be historically important: perhaps for the first time since the Industrial Revolution, there may have been a decline in global inequality. ${ }^{4}$ Between 2002 and 2008, global Gini decreased by 1.4 points. We must not rush to conclude that what we see in the most recent years represents a real or irreversible decline, or a new trend, because we do not know if the decline in global inequality will continue over the next decades. So far it is just a tiny drop, a kink in the trend, but it is indeed a hopeful sign. For the first time in almost 200 years - after a long period during which global inequality rose and then reached a 
very high plateau - it may be setting onto a downward path.

The main reason for this break in the previous trend is what also underlies the decrease in concept 2 inequality: the fast growth of relatively poor and very populous countries, most notably China and India. Their growth, reflected in the rising real incomes of their populations, has not only curbed the rise in global inequality but pushed it down slightly. China's and India's roles stand in marked contrast to the two other factors that influence global inequality and that have both been clearly pro-inequality. The first is the divergence of countries' mean incomes that lasted from around 1980 to 2000; the second is the rise in within-national inequalities in many countries. The catching up of poor and large countries has been the sole factor offsetting these upward pressures. But it has been such a strong factor that it has either kept global inequality from rising or (more recently, with the acceleration of Indian growth) reduced it.

What can we say about the level of global inequality? What does the Gini of about 70, which is the value of global inequality (see Figure 2), mean? One way to look at it is to take the whole income of the world and divide it into two halves: the richest 8 per cent will take one half and the other 92 per cent of the population will take another half. So, it is a 92-8 world. Applying the same type of division to the US income, the numbers are 78 and 22. Or using Germany, the numbers are 71 and 29. Another way to look at it is to compare what percentage of the world's population, ranked from the poorest to the richest, is needed to get to the cumulative one fifth of global income. Three quarters of the (poorer) world population are needed to get to the first fifth of total income, but only 1.7 per cent of those at the top suffice to get to the last fifth.

Global inequality is much greater than inequality within any individual country. In Figure 3, global Gini of 70 is shown together with the Ginis for several countries. Global inequality is substantially greater than inequality in Brazil, a country that is often held as an exemplar of excessive inequality (despite the recent improvements under the Lula presidency). And it is almost twice as great as inequality in the US. ${ }^{5}$

How confident are we that these numbers truly reflect what is happening to inequality among world citizens? The global inequality numbers come from calculations performed across representative national surveys that monitor incomes or consumption of households. About 120 such surveys stand behind each of the six dots shown in Figures 2 and 3. These 120 surveys include actual incomes or consumption levels for about 10 million people. This is about 0.15 per cent of the current world population - not a negligible number and, in principle, sufficiently representative for the world as a whole even if the rich have been more reluctant to participate
Figure 3. Global Gini coefficient compared to the Ginis of selected countries.

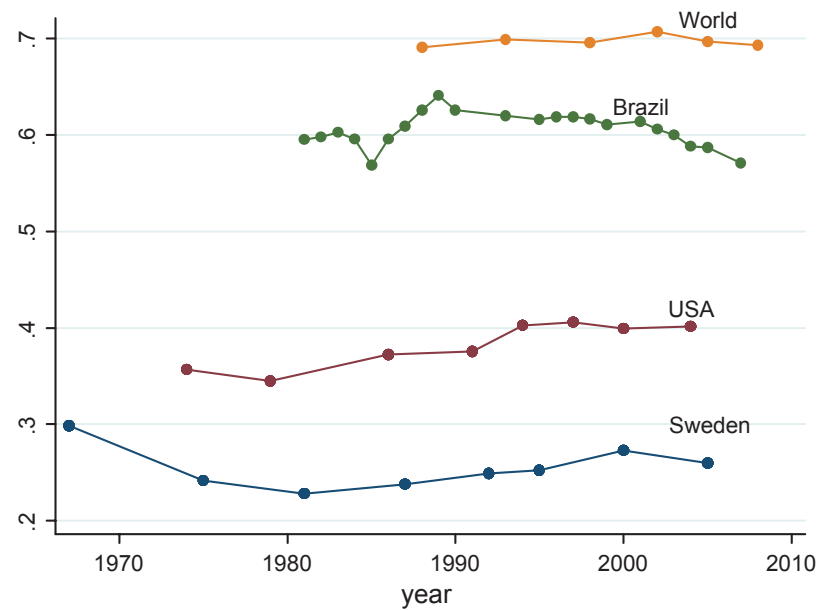

in national household surveys recently. This in turn likely imparts a downward bias to national and perhaps to global inequality estimates. ${ }^{6}$

Table 1 shows the coverage of world population by household surveys. The second row from the bottom shows the overall coverage, which was greater than 90 per cent in all years but one. This is quite good, but we should not forget that the countries that are omitted because they do not conduct household surveys are not

Table 1. Population coverage by household surveys, 19882008 (per cent)

\begin{tabular}{|c|c|c|c|c|c|c|}
\hline & 1988 & 1993 & 1998 & 2002 & 2005 & 2008 \\
\hline Africa & 48 & 76 & 67 & 77 & 78 & 75 \\
\hline Asia & 93 & 95 & 94 & 96 & 94 & 98 \\
\hline $\begin{array}{l}\text { Latin America } \\
\text { and the } \\
\text { Caribbean }\end{array}$ & 87 & 92 & 93 & 96 & 96 & 95 \\
\hline $\begin{array}{l}\text { Post-communist } \\
\text { countries }\end{array}$ & 99 & 95 & 100 & 97 & 93 & 92 \\
\hline $\begin{array}{l}\text { Rich world } \\
\text { (Western } \\
\text { Europe, North } \\
\text { America and } \\
\text { Oceania) }\end{array}$ & 92 & 95 & 97 & 99 & 99 & 97 \\
\hline World & 87 & 92 & 92 & 94 & 93 & 94 \\
\hline $\begin{array}{l}\text { Number of } \\
\text { countries } \\
\text { with household } \\
\text { surveys }\end{array}$ & 103 & 122 & 124 & 122 & 122 & 116 \\
\hline
\end{tabular}

Note: post-communist countries include Eastern European countries (many of which are members of the EU) and former Soviet republics. This is not an ideal classification, and in the future it may have to be changed. 
drawn randomly from all the countries in the world but are all poor countries such as Afghanistan, Sudan, Congo, Somalia, Eritrea, etc. This is reflected in the substantially lower population and income coverage of Africa. While the population coverage of other continents never falls below 92 per cent, African coverage at its peak is 78 per cent (see Table 1). And, in a worrisome development, the number and availability of household surveys in Africa is currently less than five or ten years ago. If we could include all of the omitted countries, global inequality would increase. In other words, what we calculate here the Gini of about 70 - is a lower bound to global inequality, simply because we do not have data from many of the poorest countries. Thus both the decreasing participation of rich individuals in national surveys and the fact that countries without surveys are overwhelmingly poor bias the global inequality numbers down.

\section{From the fall of the Berlin Wall to the global financial crisis: who won and who lost}

Generally two groups of people are thought to be the big winners of the past two decades of globalization: firstly the very rich, those at the top of national and global income distributions; secondly the middle classes of the emerging market economies, particularly China, India, Indonesia and Brazil. Is this true? Figure 4 provides an answer by showing the change in real income (measured in constant international or PPP dollars) between

Figure 4. Change in real income between 1988 and 2008 at various percentiles of global income distribution (calculated in 2005 international dollars).

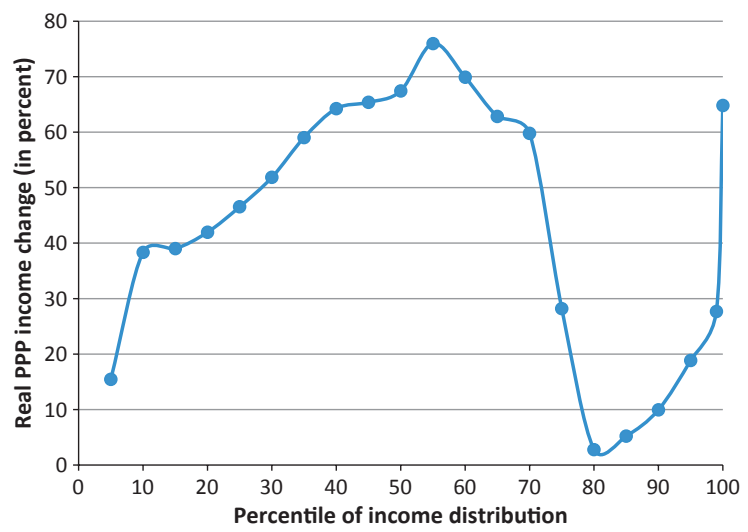

Note: the vertical axis shows the percentage change in real income, measured in constant international dollars. The horizontal axis shows the percentile position in the global income distribution. The percentile positions run from 5 to 95, in increments of five. The top 5 per cent are divided into two groups: the top 1 per cent, and those between the $95^{\text {th }}$ and $99^{\text {th }}$ percentiles.
1988 and 2008 at various percentiles of the global income distribution.

What parts of the global income distribution registered the largest gains between 1988 and 2008? As the figure shows, it is indeed among the very top of the global income distribution and among the 'emerging global middle class', which includes more than a third of the world's population, that we find most significant increases in per-capita income. The top 1 per cent has seen its real income rise by more than 60 per cent over those two decades. However, the largest increases were registered around the median: 80 per cent real increase at the median itself and some 70 per cent around it. It is between the $50^{\text {th }}$ and $60^{\text {th }}$ percentiles of global income distribution that we find some 200 million Chinese, 90 million Indians and about 30 million people each from Indonesia, Brazil and Egypt. These two groups - the global top 1 per cent and the middle classes of the emerging market economies - are indeed the main winners of globalization.

The surprise is that those in the bottom third of global income distribution have also made significant gains, with real incomes rising between over 40 per cent and almost 70 per cent. The only exception is the poorest 5 per cent of the population, whose real incomes have remained the same. This income increase at the bottom of the global pyramid has allowed the proportion of what the World Bank calls the absolute poor (people whose per-capita income is less than 1.25 PPP dollars per day) to go down from 44 per cent to 23 per cent over approximately the same 20 years.

But the biggest losers (other than the very poorest 5 per cent), or at least the 'nonwinners', of globalization were those between the $75^{\text {th }}$ and $90^{\text {th }}$ percentiles of global income distribution, whose real income gains were essentially nil. These people, who may be called a global upper middle class, include many from former communist countries and Latin America, as well as those citizens of rich countries whose incomes stagnated.

Global income distribution has changed in a remarkable way. It was probably the most profound global reshuffle of people's economic positions since the Industrial Revolution. Broadly speaking the bottom third, with the exception of the very poorest, became significantly better off and many of the people there escaped absolute poverty. The middle third or more became much richer, seeing their real incomes rise by approximately 3 per cent per capita annually.

However, the most interesting developments happened among the top quartile: the top 1 per cent, and to a somewhat lesser extent the top 5 per cent, gained significantly; the next 20 per cent either gained very little or had stagnant real incomes. This created polarization among the richest quartile of world population, allowing the top 1 per cent to pull ahead of the other rich and to 
reaffirm in fact - and even more so in public perception its preponderant role as a winner of globalization.

Who are the people in the global top 1 per cent? Despite its name, it is a less 'exclusive' club than the US top 1 per cent: the global top 1 per cent consists of more than 60 million people, the US top 1 per cent only 3 million. Thus, among the global top 1 per cent, we find the richest 12 per cent of Americans (more than 30 million people) and between 3 and 6 per cent of the richest Britons, Japanese, Germans and French. It is a 'club' that is still overwhelmingly composed of the 'old rich' world of Western Europe, Northern America and Japan. The richest 1 per cent of the embattled euro countries of Italy, Spain, Portugal and Greece are all part of the global top 1 percentile. The richest 1 per cent of Brazilians, Russians and South Africans belong there too.

To which countries and income groups do the winners and losers belong? Consider the people in the median of their national income distributions in 1988 and 2008. In 1988, a person with a median income in China was richer than only 10 per cent of the world's population. Twenty years later, a person at that same position within Chinese income distribution was richer than more than half of the world's population. Thus, he or she leapfrogged over more than 40 per cent of people in the world.

For India the improvement was more modest, but still remarkable. A person with a median income went from being at the $10^{\text {th }}$ percentile globally to the $27^{\text {th }}$. A person at the same income position in Indonesia went from the $25^{\text {th }}$ to $39^{\text {th }}$ global percentile. A person with the median income in Brazil gained as well. He or she went from being around the $40^{\text {th }}$ percentile of the global income distribution to about the $66^{\text {th }}$ percentile. Meanwhile, the position of large European countries and the US remained about the same, with median income recipients there in the $80 \mathrm{~s}$ and $90 \mathrm{~s}$ of global percentiles. But if the economic crisis that currently affects these countries persists, we should not be surprised if we find the median individual in the 'rich world' becoming globally somewhat poorer.

Who lost between 1988 and 2008? Mostly people in Africa, some in Latin America and post-communist countries. The average Kenyan went down from the $22^{\text {nd }}$ to the $12^{\text {th }}$ percentile globally, the average Nigerian from the $16^{\text {th }}$ to $13^{\text {th }}$ percentile. A different way to see this is to look at how far behind the global median was an average African in 1988 and 20 years later.

In 1988, an African with the median income of the continent had an income equal to two thirds of the global median. In 2008, that proportion had declined to less than half. The position of a median-income person in post-communist countries slid from around the $75^{\text {th }}$ global percentile to the $73^{\text {rd }}$. The relative declines of Africa, Eastern Europe and the former Soviet Union con- firm the failure of these parts of the world to adjust well to globalization, at least up to the early years of the $21^{\text {st }}$ century. Their improved recent performance is still too fragile to have been reflected in the survey data.

For 1988 and 2008 the Lorenz curves, which plot the percentage of cumulative income (running from 1 to 100 ) on the vertical axis against the percentage of cumulative population (running also from 1 to 100) on the horizontal axis, intersect in an almost textbook-like fashion (see Figure 5). Neither distribution is Lorenz-dominant. The gains at below and around the median make the Lorenz curve for 2008 lie above the one for 1988 all the way up to the $80^{\text {th }}$ percentile. For example, the bottom two thirds of the world's population received 12 . per cent of world income in 2008 compared to 9.3 per cent in 1998. But the stagnation or decline in the real income of the global upper middle class, and the big gains realized by the top 1 per cent, reverse the position of the Lorenz curves for the last one fifth of the distribution. Here, the top 1 per cent in 2008 receives almost 15 per cent of global income compared to 11.5 per cent 20 years earlier.

The bottom line is that these results show a remarkable change in underlying global income distribution. We now live in a world with a bulge around the median, with significantly rising incomes for the entire second third (or more) of the global income distribution. That is the new aspiring global middle class. We also see the

Figure 5. Lorenz curves for global income distributions in 1988 and 2008.

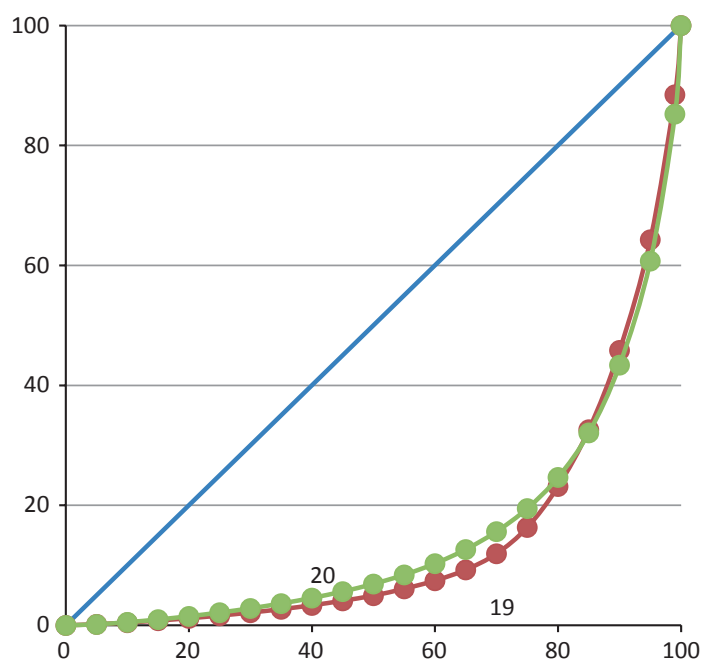

Note: the Lorenz curve shows, on the horizontal axis, the cumulative percentage of population, ranked from the poorest to the richest percentile; on the vertical axis, the cumulative percentage of total income received by such population percentiles. If, for a given value of $x, y$ is greater, it means that the bottom $x$ per cent of the population receives a greater share of total income. 
growing wealth, and probably power, of those at the very top and, remarkably, stagnant incomes for both the people just below the 'enchanted' richest 1 or 5 per cent and the world's poorest.

\section{Global inequality over the long term: from proletarians to migrants}

I will now look at global inequality over the long sweep of history. It is here that we can establish an important finding, which, I think, goes into some core issues of political philosophy and economics.

Let us try to do for the entire period since the Industrial Revolution the same type of global inequality calculations that we have just shown for the last 20 years. We ask, 'what was global inequality around the mid- $19^{\text {th }}$ century?' It is an impossible question to answer with any precision, because we do not have household surveys or any other reliable sources of income data for these times. Nonetheless, some important attempts to estimate it have been made before, notably by François Bourguignon and Christian Morrisson (2002), who were the first to take such a long-term view. They used income levels (GDP per capita) from Angus Maddison's database (2004, 2007) and some of their own (necessarily often shaky) estimates of income distributions for different parts of the world to create global income distributions for 11 benchmark years spanning the period 1820-1992. They did the best one could do with the available data; their results have been corroborated (to the extent that it is possible to corroborate something so tentative) by several later authors (Van Zanden et al., 2010; Milanovic, 2011).

The basic story that emerges from these calculations of income inequality in far-away times is that since the Industrial Revolution, which launched a score of European countries and their overseas offshoots onto a path of faster growth, global inequality kept on rising until the mid- $20^{\text {th }}$ century. There was a period of more than a century of steady increase in global inequality, followed by perhaps 50 years (between the end of the Second World War and the turn of the $21^{\text {st }}$ century) when global inequality remained on a high plateau, changing very little. We can see this in Figure 2, where the six dots are all within several Gini points of each other; that is, within one standard error of the calculated Gini coefficients. It is only in the early $21^{\text {st }}$ century that global inequality might have commenced its downward course. If indeed this comes to pass, global inequality would have charted a gigantic inverted U-shaped curve and perhaps in some 50 years - if the emerging market economies continue to grow faster than the rich world - we might be back to the state of affairs that existed around the time of the Industrial Revolution.
But, for now, we are still very far from it. And perhaps nothing shows it better than Figure 6 . There, the height of the bar represents the Theil coefficient of global inequality in two baseline years: 1870 and 2000.7 The height of the bar is much greater now, meaning that global inequality today is greater than in 1870 - which, of course, is not a surprise. ${ }^{8}$

What is less obvious and less well known is that the shares of the two factors determining global inequality have changed in a remarkable fashion. Global inequality can be decomposed into two parts. The first part results from differences in incomes within nations, which means that that part of total inequality is caused by income differences between rich and poor Americans, rich and poor Chinese, rich and poor Egyptians and so on for all the countries in the world. If one adds up all of these withinnation inequalities, one gets their aggregate contribution to global inequality. This is what I call the 'class' component to global inequality because it accounts for (the sum of) income inequalities between different 'income classes' within countries. The second component, which I call the 'location' component, refers to the differences between the mean incomes of all the countries in the world. So there, one actually asks 'how much are the gaps in average incomes between the UK and China, between The Netherlands and India, between the US and Mexico and so on influencing global inequality?' It is the sum of inter-country differences in mean incomes. In technical terms, the first part ('class') is also called 'within inequality'; the second part ('location') is called 'between inequality'.

Figure 6 plots these two parts for the years 1870 and 2000. Around 1870, class explained more than two thirds of global inequality. And now? The proportions have exactly flipped: more than two thirds of total inequality is due to location. The implication of this overwhelming importance of location, or citizenship (which is the same) i.e. being a member of a rich or poor country - for our lifetime incomes can also be captured very well by another exercise. We divide the population of each country into 100 income percentiles, ranked from the poorest to the richest. Now, if we run a regression with income levels of these percentiles (for 120 countries, this gives 12,000 observations) as the dependent variable, and on the other side of the regression use the mean income of the country where each percentile comes from as the only explanatory variable, we explain more than half of the variability in individual incomes. This is a remarkable achievement for a single explanatory variable. Differently put, more than 50 per cent of one's income depends on the average income of the country where a person lives or was born (the two things being the same for 97 per cent of world population). This underlines the importance of the location element today. There are, of course, other factors that matter for one's income: from gender and 
Figure 6. A non-Marxian world: level and composition of global inequality in the $19^{\text {th }}$ century and around 2000 (measured by the Theil index).

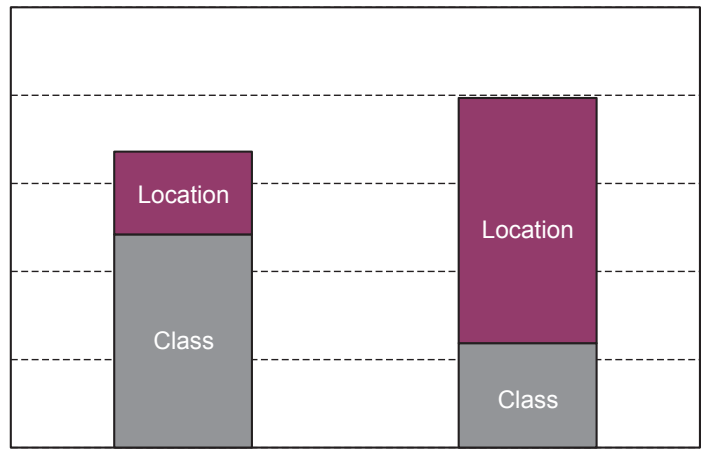

Note: I use Theil mean log deviation because it is exactly decomposable (between 'class' and 'location') and because the importance of each component does not depend on the rest of the decomposition. Anand and Segal (2008), in a review of global inequality studies, suggest that it is the most appropriate inequality index for this kind of decomposition.

parental education (which are, from an individual point of view, externally given circumstances) to factors like own education, effort and luck (which are not). They all influence our income level. But the remarkable thing is that a very large chunk of our income will be determined by only one variable, which generally we acquire at birth: citizenship. It is almost the same as saying that if I know nothing about any given individual in the world I can, with a reasonable amount of confidence, predict his or her income just from the knowledge of his or her citizenship.

As stated in the title of Figure 6, we live today in a non-Marxian world. Karl Marx could write eloquently in 1867 in Das Kapital, or earlier in The Manifesto, about proletarians in different parts of the world - peasants in India, workers in England, France or Germany - sharing the same political interests. They were invariably poor and, importantly, they were all about equally poor, eking out a barely-above-subsistence existence, regardless of the country in which they lived. There was not much of a difference in their material positions. One could imagine and promote proletarian solidarity, and consequently - because equally poor people of different nations faced equally rich people in their own nations - a generalized class conflict. This was the idea behind Trotsky's 'permanent revolution'. There were no national contradictions, just a worldwide class contradiction. This was a broadly accurate description of the situation at that time.

But if the world's actual situation is such that the greatest disparities are caused by the income gaps between nations, then proletarian solidarity does not make much sense. Indeed, the income levels of poor individuals in poor countries are much lower than those of poor people in rich countries. People who are considered nationally poor in the US or the EU have incomes that are many times greater than incomes of the poor people in poor countries and, moreover, often greater than the incomes of the middle class in poor countries. And if that gap is so wide, then one cannot expect any kind of coalition between such income-heterogeneous groups of nationally poor people - or at least not any coalition based on the similarity of their material positions and near identity of their economic interests. Proletarian solidarity is dead because there is no longer such a thing as the global proletariat. This is why ours is a distinctly non-Marxian world. But what kind of the world is it? I turn to this question next.

\section{Gaps between country incomes today}

In Milanovic (2012), I have argued that a proper analysis of global inequality today requires an empirical and mental shift from concerns with class to concerns with location; in other words, a movement 'from proletarians to migrants'. This was meant to summarize a macro-development that has taken place over the last two centuries. If the main determinant of one's income is now location, who are the underdogs? People who live in poor countries. And what do underdogs want to do? They want to become richer at home or, failing that, to migrate to richer places.

To illustrate the difference in the economic positions of people from different countries, I resort to the same exercise as was sketched earlier: I divide the populations of all countries into groups of 5 per cent (called ventiles, because there are 20 such groups in a population) running from the poorest to the richest. This is shown on the horizontal axis of Figure 7: the poorest ventile in any country will be at $x=1$. Consider, for example, the poorest 5 per cent of people in the US. I put them all together, and calculate their average income; I then do the same for the next 5 per cent, then for the next 5 per cent - all the way to the very richest ventile. The poorest 5 per cent of Americans are making around $\$ 3,000-4,000$ per capita per year. How do they compare with the rest of the world? In what percentile of the global income distribution would they be? This is shown on the vertical axis. We can start with an intuition: poor Americans are unlikely to be among the poorest people globally speaking, because their incomes are not that low. For example, we know that some 20 per cent of the world's population lives on less than 1 international dollar per day, while the US poverty line (below which, in principle, nobody in the US should fall) is $\$ 13$ per day. Thus, based on such very limited evidence, we can already expect the poorest Americans to be relatively high up in the global income distribution. Indeed, as shown by the 
graph, the poorest Americans are at the $60^{\text {th }}$ percentile of world income distribution. This means that they have a higher annual income than 60 per cent of the world's population. As one moves higher up the US income distribution, each richer ventile of Americans will obviously stand even higher in the world income distribution. The richest 5 per cent of Americans belong to the global top 1 per cent. (With a more detailed and finer partitioning it can be shown that the top 12 per cent of Americans are all part of the highest global percentile, as we saw in Section 2.)

How does the same calculation look for a country like India? The very top of the income distribution in India overlaps with the very bottom of the income distribution in the US. Clearly, there are millionaires in India as well as people who are quite rich; the same graph with percentiles (rather than ventiles) would have shown the top end of India's income distribution to be a little bit higher, but even in that case it would not go past the global $80^{\text {th }}$ percentile. So these rich Indians, as a group, barely match the average income of middle-class Americans. Note that these are indeed very large groups of people and that the averages may conceal some very high individual incomes: if I use ventiles, each Indian ventile consists of some 60 million people; if I use percentiles, each percentile is 12 million people. The latter figure is equal to the population of the municipality of Mumbai. But the key point is that although there are some very rich people in India, and even some extravagantly rich people, their numbers are not statistically significant; the number of people who enjoy the standard of living of the American middle class is still very limited.

Consider the same graph for China. China dominates India throughout the whole income distribution (people at a given percentile level of Chinese distribution always have higher income than people at that same percentile of India's income distribution), and the Chinese top ventile attains almost the $80^{\text {th }}$ percentile of the world's income distribution. Had we used percentiles, the top 1 per cent of the Chinese would be better off than 93 per cent of the world's population.

Now consider Brazil. Not surprisingly, Brazil mimics the world. The poorest people in Brazil are at the bottom of the global income distribution, among the poorest people in the world, while its large middle class enjoys income levels that place it between the $70^{\text {th }}$ and $80^{\text {th }}$ percentiles in the world. At the very top, the richest Brazilians are part of the top one or two global percentiles.

Figure 8 , displayed in exactly the same fashion as Figure 7 , is dedicated to Italy but could have represented any important migration-receiving country - the US, Germany, France or Spain. In the figure, Italy's distribution is compared with that of the world, and then with Germany and with the distributions of the countries providing the bulk of immigrants into Italy. First, where is Italy compared
Figure 7. Different countries and income classes in global income distribution, 2005.

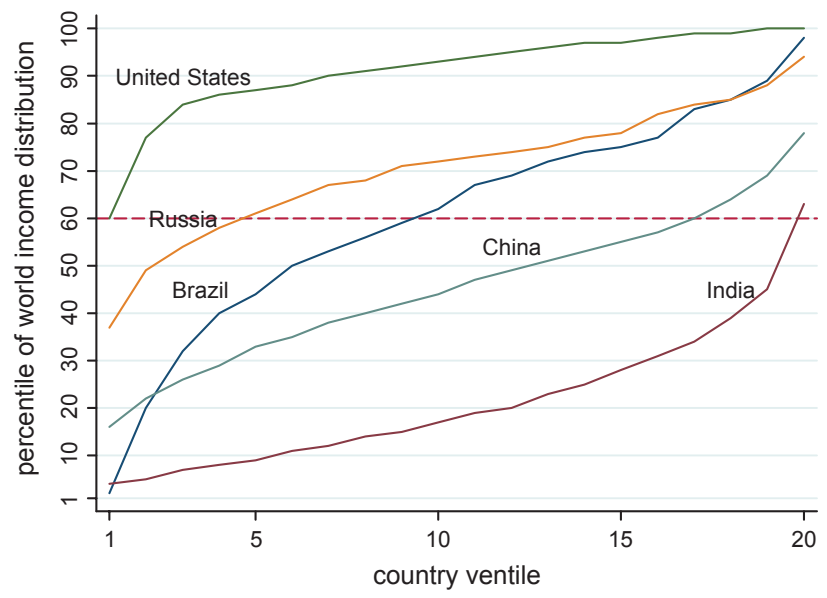

Note: the line drawn at $y=60$ shows the global position of the poorest 5 per cent of the US population.

Figure 8. Italy and the rest of the world.

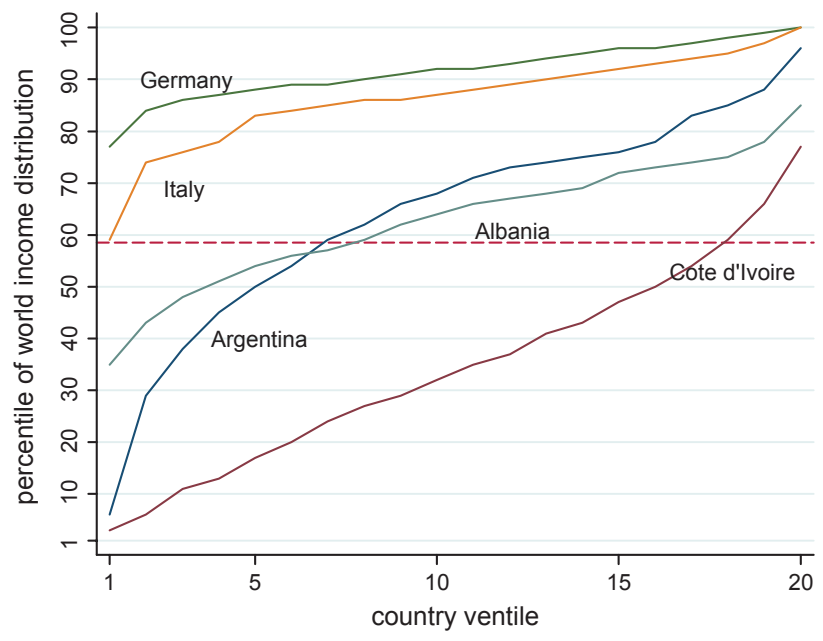

to the rest of the world? Its poorest people are just below the $60^{\text {th }}$ global percentile, which is, as we just saw, approximately the same percentile as the poorest Americans. As we move toward the richer Italian ventiles, their global position (obviously) improves. The richest 5 per cent of Italians are at the top of the world; that is, among the top global percentile.

Now compare Italy with Germany. What stands out is the very high income level of the bottom ventiles for Germany. The same would be true if instead of Germany we used Denmark, Norway or other Nordic countries. The people at the bottom of the income distributions in those countries are around the $80^{\text {th }}$ percentile of world income distribution or higher. The poorest Danes are at 
the $90^{\text {th }}$ percentile, while in countries like Mozambique and Uganda not even the top ventile reaches further than the $65^{\text {th }}$ percentile. The poorest Danes (as a group) are richer than the richest Ugandans (as a group).

To zero in on the importance of citizenship and consequently migration, it is useful to compare the data for Italy with those for the countries from which most of migrants into Italy come. This is because the major implication of a world where location matters is that migration can increase a person's income significantly. The way to improve one's standard of living is simply to move to a richer country. In Albania, about 40 per cent of the population have incomes that are below the poverty threshold of Italy; obviously these people, even if after migration they were to become the poorest people in Italy, would still improve their real income. The same is true for Argentina: a very high percentage - about a quarter of the population - have incomes that are below the Italian de facto poverty threshold. And finally consider the Ivory Coast as a representative of African countries. There, a staggering 80 per cent of the population live below the Italian poverty threshold. So if these 80 per cent of Ivoirians were to move to Italy, they would all become better off - even if they were just to join the poorest Italians.

\section{Concluding remarks: philosophical reflections and political implications}

I want to conclude with two points that I think can be derived from what I have discussed so far.

The first one is an issue for political philosophy. If most of global inequality is due to differences in location, can we treat location, and thus citizenship, as a rent or a premium (or, conversely, as a penalty)? Is citizenship belonging to a given country, most often through birth something that gives us by itself the right to greater income? Is there a difference in our view of the matter if we take a global, as opposed to national, perspective? Is there a contradiction between the two?

Within a single country, society tries in principle to limit the advantages that accrue to people born in rich families. The advantages include access to better education and health care, to powerful friends and private information, and of course greater wealth. Society tries to limit these inherited advantages by either taxing wealth or by making education, health etc available to all, regardless of their income level. But what is the case in the 'global world'? The situation is, at one level, very similar. There are rich countries that have accumulated lots of wealth and transmit that wealth, along with many other advantages, to the next generations of their citizens. This is why, for example, the poorest Americans are relatively well off by world standards. They are lucky to have been born in the country that is rich (or has become rich: the case was different for the poorest Americans in the $17^{\text {th }}$ century). And there are also people from poor countries who do not have wealth or the advantages and opportunities it confers. In stark contrast to the within-country case, this is considered unobjectionable; or rather it is not questioned whether one may keep on benefiting from something that the previous generations have created and one has simply inherited by virtue of birth. In one case, we frown upon the transmission of family-acquired wealth to offsprings if two different individuals belong to the same nation. In the other case, we take it as normal that there is a transmission of collectively acquired wealth over generations within the same nation, and if two individuals belong to two different nations we do not even think about, much less question, such acquired differences in wealth, income and global social position.

In political philosophy, there are good arguments to go on with that approach (as we do implicitly today) and there are also good arguments to disapprove of it. It is hard to decide which way is right. But what we can do is to put that argument on the table and open it for discussion.

The second implication concerns the issue of migration. If citizenship explains 50 per cent or more of variability in global incomes, then there are three ways in which global inequality can be reduced. The first is by high growth rates of poor countries. This requires an acceleration of income growth in poor countries, and of course continued high rates of growth in India, China, Indonesia, etc. The second way is to introduce global redistributive schemes. Yet it is very difficult to see how that could happen. Currently, development assistance is a little over $\$ 100$ billion a year. This is just five times more than the bonus Goldman Sachs paid itself during one crisis year. Rich countries are not willing to spend very much money to help poor countries. The willingness to help poor countries is now, with the ongoing economic crisis in the west, probably reaching its nadir. The third way in which global inequality and poverty can be reduced is through migration. Migration is likely to become one of the key problems - or solutions, depending on one's viewpoint - of the $21^{\text {st }}$ century. To give just one stark example: if you classify countries by their GDP per capita level into four 'worlds', going from the rich world of advanced nations (with GDPs per capita of over $\$ 20,000$ per year) to the poorest, fourth, world (with incomes under $\$ 1,000$ per year), there are seven points in the world where rich and poor countries are geographically closest to each other - whether it is because they share a border, or because the sea distance between them is minimal. You would not be surprised to find out that all seven of these points have mines, boat patrols, walls and fences to prevent free movement of people. ${ }^{9}$ The rich world is fencing itself in, or fencing 
others out. But the pressures of migration are remaining strong, despite the current crisis, simply because the differences in income levels are so huge.

I conclude with something that resembles a slogan: either poor countries will become richer, or poor people will move to rich countries. Actually, these two developments can be seen as equivalent. Development is about people: either poor people have ways to become richer where they are now, or they can become rich by moving somewhere else. Looked at from above, there is no real difference between the two options. But from the point of view of real politics, there is a whole world of difference.

\section{Notes}

The author is grateful to Michele Bocchiola, Pietro Reichlin, Sebastiano Maffetone and Leif Wenar for their comments.

1. This paper was first presented at the Conference on Global Justice held at the Libera Universita Internazionale degli Studi Sociali (LUISS) in Rome on 6-9 June 2012. It is written as part of the Knowledge for Change Project-funded project 'Changeable inequalities: facts, perceptions and policies', TF012968. The interpretations and conclusions of this article are entirely the author's. They do not necessarily represent the views of the World Bank and its affiliated organizations, or those of the governments they represent.

2. The Gini coefficient is a statistical measure of inequality that takes its name from the Italian statistician and economist Corrado Gini. The Gini index is the most frequently used measure of inequality: it ranges from 0 , when everybody has the same income, to 1 or 100 (expressed as a percentage or an index), when one person gets the entire income of a city (province, nation, world) - whatever is the relevant population over which we calculate inequality.

3. The coverage is always greater for total world income than for population because countries that do not have household surveys are generally poor countries whose importance in global output is small.

4. Our knowledge of the long-term evolution of global inequality is indeed very tentative as far as exact levels are concerned, but is very clear in terms of broad tendencies since the mid- $19^{\text {th }}$ century: the Industrial Revolution, by creating a massive divergence between the rich western countries and the rest of the world, pushed global inequality up (see also Section 3 ).

5. The vertical axis in Figure 3 shows Gini coefficient in its 'natural' values, i.e. not in percentages. Thus a Gini of 0.7 displayed there is the same as a Gini of 70 . For simplicity, we use the second approach throughout this article.

6. The effects of nonparticipation in surveys on measured inequality is, by definition, difficult to estimate because the income of people who refuse to participate is not known. We can conclude only indirectly (e.g. by looking at the geographical distributions of refusals as in Korinek et al., 2005) that the rich comply less.
The difficulty in figuring out the effects of the rich's nonparticipation exists despite the intuition that it must underestimate actual inequality. In a model proposed by Angus Deaton (2005), where compliance decreases with income following a Pareto-like function, the standard deviation of income distribution does not change and inequality, by most measures, is unaffected. However, with different noncompliance functions, inequality may indeed be underestimated.

7. Theil coefficient, named after the Dutch econometrician Henri Theil, is another way to measure inequality. It is not as popular, nor is its meaning as intuitive, as Gini, but in this case - when we have to decompose inequality into two components - Theil coefficient is preferable to Gini, whose decomposition is not 'exact'. That is, with the Gini there is a residual term whose interpretation is not always clear.

8. The results would have been the same with the Gini.

9. They are the US-Mexican, Greek-Macedonian (or Albanian), Saudi -Yemeni, North-South Korean and Israeli-Palestinian land borders, and the Spanish-Moroccan and Malaysian-Indonesian sea borders.

\section{References}

Anand, S. and Segal, P. (2008) 'What Do We Know about Global Income Inequality?, Journal of Economic Literature, 1, p. 85.

Bourguignon, F. and Morrisson, C. (2002) 'The Size Distribution of Income among World Citizens, 1820-1990', American Economic Review, 92 (4), pp. 727-744.

Deaton, A. (2005) 'Measuring Poverty in a Growing World', Review of Economics and Statistics, 87 (1), pp. 1-19.

Korinek, A., Mistiaen, J. A. and Ravallion, M. (2005) Survey Nonresponse and the Distribution of Income. World Bank Policy Research Working Paper 3543, March 2005. Washington, DC: World Bank.

Maddison, A. (2004) 'World Population, GDP and GDP per capita, 1-2000 AD' [online]. Available at http://www.ggdc.net/MADDISON/ oriindex.htm [Accessed 18 January 2012].

Maddison, A. (2007) Contours of the World Economy, 1-2030: Essays in Macro-economic History. Oxford: Oxford University Press.

Milanovic, B. (2011) 'Global Inequality and the Global Inequality Extraction Ratio: the Story of the Past Two Centuries', Explorations in Economic History, 48, pp. 494-506.

Milanovic, B. (2012) 'Evolution of Global Inequality: from Class to Location, from Proletarians to Migrants', Global Policy, 3 (2), pp. 125-134.

Van Zanden, J. L., Baten, J., Foldvari, P. and van Leeuwen, B. (2010) The Changing Shape of Global Inequality, 1820-2000. Typescript, Working paper 001, Utrecht University, Centre for Global Economic History. December 2010.

\section{Author Information}

Branko Milanovic is Lead Economist at the World Bank's Development Research Group, Poverty and Inequality Unit. 